\title{
Envolvimento paterno na mídia: publicações em revistas para pais e mães
}

\section{Father involvement in media: publications in magazines for parents}

\section{Envolvimiento paterno en los medios de comunicación: publicaciones en revistas para padres y madres}

\author{
Isabella Goulart Bittencourt* \\ Universidade Federal de Santa Catarina, Florianópolis, Santa Catarina, Brasil \\ Larissa Paraventi** \\ Universidade Federal de Santa Catarina, Florianópolis, Santa Catarina, Brasil
}

Rovana Kinas Bueno***

Universidade Federal de Santa Catarina, Florianópolis, Santa Catarina, Brasil

\author{
Gabriela Mello Sabbag**** \\ Universidade Federal de Santa Catarina, Florianópolis, Santa Catarina, Brasil
}

Maria José Louise Caro Schulz*****

Universidade Federal de Santa Catarina, Florianópolis, Santa Catarina, Brasil

Mauro Luís Vieira******

Universidade Federal de Santa Catarina, Florianópolis, Santa Catarina, Brasil

\begin{abstract}
RESUMO
Com as mudanças no contexto familiar, o pai vem ampliando seu papel, sendo a mídia um dos instrumentos que comunica, transmite e produz discursos sobre a paternidade. Neste estudo, tem-se como objetivo analisar - que as revistas Pais \& Filhos e Crescer publicam sobre o pai e o envolvimento paterno. Para isso, sortearam-se 30 exemplares de cada revista, três por ano, de 2003 até 2013. Leram-se as reportagens e foram selecionadas as que se referiam ao pai. As 104 reportagens selecionadas da Revista Pais \& Filhos e 94 da Revista Crescer foram analisadas conforme o conteúdo categorial temático segundo Bardin, utilizando-se o software ATLAS.ti. Como resultados, têm-se as categorias paternidade e família, com nove e cinco elementos temáticos respectivamente. Os elementos temáticos predominantes em paternidade são: o novo pai $(n=58)$, pai como modelo $(n=48)$ e papel do pai $(n=41)$. Já relações familiares $(n=36)$, educação de filhos $(n=34)$ e conjugalidade e paternidade $(n=27)$ predominaram na categoria família. Portanto, com base na análise dos dados, conclui-se que as revistas pesquisadas apontam para uma imagem de pai envolvido, que
\end{abstract}


Isabella Goulart Bittencourt, Larissa Paraventi, Rovana Kinas Bueno, Gabriela Mello Sabbag, Maria José Louise Caro Schulz, Mauro Luís Vieira

interage com seu filho, disponibiliza-se e se responsabiliza pelos cuidados à criança.

Palavras-chave: relações pai-filho, paternidade, mídia.

\section{ABSTRACT}

With the changes in the family context, the father has been expanding his role, and the media is an instrument that communicates, transmits and produces discourses about fatherhood. In this study, the aim is analyze what the magazines Pais \& Filhos and Crescer publish about father and father involvement. For this, 30 copies of each magazine were raffled up, three a year, from 2003 until 2013. The articles were read and those that referred to the father were selected. The 104 articles selected from Pais \& Filhos Magazine and 94 from Crescer Magazine were analyzed according to categorical thematic content of Bardin, using the ATLAS.ti software. In the results, there are the fatherhood and family classes, with nine and five thematic elements respectively. The predominant thematic elements in fatherhood are: the new father $(n=58)$, father as a model $(n=48)$ and role of the father $(n=41)$. Familiar relationships $(n=36)$, education of children $(n=34)$ and marital and fatherhood $(n=27)$ predominated in the family category. Therefore, according to the data analysis, we conclude that the magazines show an image of father involved, who interacts with his child, provides up and is in charge for child care.

Keywords: relation father-child, fatherhood, media.

\section{RESUMEN}

Con los cambios en el contexto familiar, el padre ha venido ampliando su papel, siendo los medios de comunicación uno de los instrumentos que comunica, transmite y produce discursos sobre la paternidad. En este estudio, el objetivo es analizar lo que las revistas Pais \& Filhos y Crescer publican sobre el padre y el envolvimiento paterno. Para esto, fueron sorteados 30 ejemplares de cada revista, tres por ano, de 2003 hasta 2013. Se leyeron los reportajes y fueron seleccionados los que se referían al padre. Los 104 reportajes seleccionados de la Revista Pais \& Filhos y 94 de la Revista Crescer fueron analizadas conforme el contenido categorial temático según Bardin, se utilizó el software ATLAS-ti. Como resultados, se destacan las categorías paternidad y familia, con nueve y cinco elementos temáticos respectivamente. Los elementos temáticos predominantes en paternidad son el nuevo padre $(n=58)$, padre como modelo $(n=48)$ y papel del padre $(n=41)$. Ya relaciones familiares $(n=36)$, educación de hijos $(n=34)$ y matrimonio y paternidad $(n=27)$ predominaron en la categoría familia. Por tanto, con base en análisis de datos, se concluye que las revistas apuntan para un padre envuelto, que interacciona con su hijo, está disponible y se responsabiliza por los cuidados del niño.

Palabras clave: relaciones padre-hijo, paternidad, medios de comunicación.

\section{Introdução}

Embora o modelo familiar tradicional, no qual o pai é o principal provedor do sustento financeiro da família, faça-se presente em muitos lares brasileiros, está cada vez mais comum a existência de um funcionamento familiar em que as tarefas domésticas e os cuidados dos filhos são divididos entre pai e mãe, mesmo que não de 
forma igualitária, estabelecendo um novo modelo (emergente) de paternidade: o novo pai. Essas mudanças possivelmente aconteceram por influência da emancipação feminina (Vieira et al., 2013) e proporcionaram transformações para 0 homem e para sua experiência da paternidade (Beltrame \& Bottoli, 2010; Gomes \& Resende, 2004; Staudt \& Wagner, 2008). Desta forma, a construção da paternidade está intrinsecamente associada às transformações e aos diferentes contextos sociais, culturais e históricos (Manfroi, Macarini, \& Vieira, 2011).

Por meio da análise de estudos realizados (Bossardi, Gomes, Vieira, \& Crepaldi, 2013; Bossardi \& Vieira, 2010), averigua-se que os pais ${ }^{1}$ estão cada vez mais oferecendo suporte emocional aos filhos, buscando disciplinar, ensinar e impor limites, bem como brincar de lutar, correr e fazer cócegas. Além disso, Paquette, Bolté, Turcotte, Dubeaud e Bouchard (2000) alegam que o pai tende a realizar brincadeiras mais intensas e agitadas do que a mãe e também a estimular as crianças a explorarem novos ambientes e enfrentarem novos desafios, o que foi denominado por estes pesquisadores de "abertura ao mundo". Embora os cuidados básicos (como preparar a comida e alimentar a criança, cuidar da higiene e das vestimentas desta) e as atividades domésticas estejam sendo cada vez mais realizados pelos homens, ainda são as mulheres as principais responsáveis pelos cuidados dos filhos e da casa (Bossardi et al., 2013; Bueno, 2014; Lamb, 1997; Staudt \& Wagner, 2008). É importante destacar que apesar de muitas vezes o pai não exercer tais tarefas diretamente, o mesmo contribui indiretamente, por meio de seu papel de provedor ou oferecendo apoio e suporte à mãe da criança (Bossardi \& Vieira, 2010; Manfroi et al., 2011).

O envolvimento paterno caracteriza-se por três dimensões específicas que se referem diretamente ao pai: interação, disponibilidade e responsabilidade (Lamb, Pleck, Charnov, \& Levine, 1985). A interação diz respeito ao contato direto do pai com seu filho por meio de atividades e brincadeiras; a disponibilidade compreende o potencial de acessibilidade física e psicológica do pai para interação (pai presente ou acessível para o filho ocorrendo a interação direta ou não); e a responsabilidade corresponde ao papel que o pai assume para garantir cuidados à criança, proporcionando recursos materiais que promovem o sustento da família (Lamb et al., 1985; Lamb, 1997). Há, ainda, outras dimensões de envolvimento paterno exploradas na literatura, baseadas em Lamb (1997) e inseridas dentre interação, disponibilidade e responsabilidade: pai em interação; pai que cuida; pai afetuoso; pai responsável; pai provedor; e pai evocativo (Dubeau, Devault, \& Paquette, 2009).

É possível investigar o envolvimento paterno de diferentes maneiras: observação direta (Paquette \& Bigras, 2010), questionários (Bossardi et al., 2013) e entrevistas (Beltrame \& Bottoli, 2010). A coleta de 
informações sobre o pai ainda pode ser realizada por meio de outras pessoas, como as mães das crianças, por exemplo (Crepaldi, Andreani, Hammes, Ristof, \& Abreu, 2006; Dessen \& Oliveira, 2013). Além disso, é possível pesquisar sobre o pai em documentos de veiculação pública, como jornais e revistas de divulgação sobre notícias relacionadas à família. Assim, a mídia é um instrumento de comunicação que transmite e produz discursos sobre a paternidade (Hennigen, 2010), além de captar e reforçar mudanças culturais (Ribeiro \& Siqueira, 2007).

A mídia, ao longo dos séculos XIX e XX, tornou-se cada vez mais atuante e um influente meio de transmissão de ensinamentos e normas a serem seguidas. Revistas, programas televisivos, telejornais, filmes e propagandas são instrumentos que transmitem tais discursos normativos. Como consequência, muitos homens sentem-se inseguros ou culpados quando não se percebem como "bons pais", ou seja, quando notam que não estão de acordo com o parâmetro veiculado pela mídia (Schwengber \& Silveira, 2011).

Pesquisar o que é publicado em mídias de divulgação, canal importante de comunicação entre o conhecimento e o seu público leitor, permite entender quais são as concepções vigentes sobre determinado tema. Nesse sentido, muitas vezes as reportagens trazem informações sobre o cotidiano do leitor e explicações sobre como é a realidade onde ele vive. Além disso, o público que consome essas mídias de divulgação é considerável, como pode ser constatado pelo volume de exemplares que são comercializados. Portanto, podese considerar as revistas como uma importante fonte de informação sobre o fenômeno a ser estudado.

No estudo realizado por Nascimento et al. (2013), investigaram-se as representações sociais da paternidade na coluna "Conversa de Homem" da revista Pais \& Filhos entre 1969 a 2008 (40 exemplares). Os pesquisadores apontaram que o novo pai não é enfatizado e que as reportagens mostram o pai em um lugar de coadjuvante ou 0 identificam como um causador de problemas. Entretanto, Chechi e Hillesheim (2008) buscaram discutir como a mídia representa os sentimentos que envolvem a paternidade na contemporaneidade na mesma coluna da revista. Para isso, foram selecionadas e analisadas as edições de junho a dezembro de 2006 , as quais demonstram que há a construção de um pai participativo na educação e na vida dos filhos desde a gravidez, bem como uma idealização da paternidade. Corroborando com tal pesquisa, Schwengber e Silveira (2011) encontraram que nos relatos feitos pelos homens, eles afirmaram ajudar no cuidado com as crianças, mostrando-se preocupados com a educação e bem-estar dos filhos. Esses resultados também foram concluídos a partir de um levantamento da seção "Coluna de Homem" das edições impressas e online de janeiro a julho de 2009. 
Identificou-se, assim, que há uma diferença entre os resultados encontrados no trabalho de Nascimento et al. (2013) se comparados aos achados por Chechi e Hillesheim (2008) e Schwengber e Silveira (2011), o que permite constatar que há perspectivas e realidades distintas sobre a paternidade. Percebe-se, portanto, a importância da mídia na divulgação do que se tem denominado novo pai, nas transformações ocorridas ao longo do tempo no papel e no envolvimento paterno.

Considerando essa relevância social e o fato de haver distinção nos resultados das pesquisas realizadas sobre o assunto, o presente estudo teve como intuito analisar o que as revistas Pais \& Filhos e Crescer publicaram sobre o pai e o envolvimento paterno, dos anos de 2003 a 2013. Optou-se por analisar as reportagens desta última década, pois, conforme Oliveira e Silva (2011), a paternidade começou a ser mais evidenciada na literatura científica brasileira principalmente a partir do ano de 2004, ressaltando que, antes desse período, o pai aparecia nos estudos geralmente como coadjuvante no processo de desenvolvimento da criança.

\section{Método}

Este estudo teve caráter exploratório e descritivo e foi realizado por meio de um levantamento de dados documental de duas revistas de circulação nacional: Pais \& Filhos e Crescer, lançadas em 1968 e 1993, respectivamente. A primeira revista mencionada é publicada pela Editora Manchete, situada na cidade de São Paulo. Já a Crescer tem como editora a Globo, localizada na cidade do Rio de Janeiro. Foram selecionados aleatoriamente 30 exemplares de cada revista, sendo três por ano, de 2003 até 2013. Essa seleção aconteceu por meio de sorteio de três meses de cada ano para cada revista e foram lidas todas as revistas sorteadas. Foram consultados exemplares entre o de número 114 (maio/2003) ao de 236 (outubro/2013) da revista Crescer entre 413 (agosto/2003) até 524 (novembro/2013) da Pais \& Filhos. Em ambos os casos, selecionaram-se as reportagens que se referiram, de alguma forma, ao pai. O critério de escolha das reportagens foi que tivessem as palavras-chave "pai", "paterno", "paternidade", "paterna" e "pais" (referindo-se aos homens). Como critério de exclusão tem-se as reportagens que não tinham como foco o pai (mesmo tendo as palavras-chave mencionadas).

Para uma maior fidedignidade na escolha das reportagens, realizouse o cálculo de concordância entre juízes, que é uma equação utilizada em métodos observacionais (Fagundes, 1999). Assim, todas as reportagens selecionadas foram enviadas a três juízas, também pesquisadoras, as quais leram e assinalaram se concordam ou não com a inclusão de cada uma das reportagens para posterior análise. 
A concordância das juízas com as pesquisadoras foi de respectivamente $93 \%, 82 \%$ e $89 \%$. Esse cálculo resulta de um somatório dos acordos da juíza com a pesquisadora, dividido pelo somatório desses acordos, mais o somatório dos desacordos e o resultado se multiplica por 100 para resultar em uma porcentagem. Como a concordância foi superior a $70 \%$, consideraram-se as escolhas adequadas.

Excluiu-se o exemplar 125 da Revista Crescer, referente ao mês de abril de 2004, pois não apresentou nenhuma reportagem sobre o pai. Assim, sorteou-se outra edição para substituí-lo (exemplar 129, agosto/2004). Selecionou-se um total de 198 reportagens para análise qualitativa, sendo 104 da revista Pais \& Filhos e 94 da Crescer. Utilizaram-se as seguintes técnicas de análise de conteúdo sugeridas por Bardin (1977): leitura flutuante das reportagens; nova leitura para identificação dos elementos temáticos (unidades mínimas de análise); e categorização dos elementos temáticos, utilizando-se o software ATLAS.ti 5.0 para organização dos dados. Este software permite a organização dos registros, facilitando a visualização dos trechos das reportagens, bem como a contabilização e agrupamento dos elementos temáticos.

\section{Resultados}

Com a leitura do conteúdo das revistas, constatou-se a predominância de duas temáticas: paternidade e família, as quais foram elaboradas por meio dos agrupamentos de nove e cinco elementos temáticos, respectivamente, conforme consta na Tabela 1. No que diz respeito ao ano, encontram-se mais matérias e reportagens em 2011, com a ocorrência de 30 reportagens, seguido pelos anos de $2008(n=22), 2004$ e $2005(n=19)$. Em relação a quem relata acerca da paternidade, foi encontrado que o pai discorre mais a respeito dele próprio, se comparado aos filhos, à esposa, aos profissionais e à editora da revista. 
Tabela 1:

Categorias e elementos de análise com respectivas frequências de ocorrência

\begin{tabular}{|c|c|c|}
\hline Categorias & Elementos temáticos & Frequência \\
\hline \multirow{9}{*}{ Paternidade } & Novo pai & 58 \\
\hline & Pai como modelo & 48 \\
\hline & Papel do pai & 41 \\
\hline & Impacto da Paternidade & 33 \\
\hline & Processo de se tornar pai & 30 \\
\hline & Brincadeiras e esporte & 24 \\
\hline & $\begin{array}{l}\text { Dificuldades enfrentadas } \\
\text { pelo pai }\end{array}$ & 15 \\
\hline & Ausência do pai & 12 \\
\hline & Dia dos pais & 3 \\
\hline \multirow{5}{*}{ Familia } & Relações familiares & 36 \\
\hline & Educação de filhos & 34 \\
\hline & $\begin{array}{l}\text { Conjugalidade } \\
\text { paternidade }\end{array}$ & 27 \\
\hline & $\begin{array}{l}\text { Diferença entre pai e } \\
\text { mãe }\end{array}$ & 24 \\
\hline & Questões juridicas & 22 \\
\hline
\end{tabular}

Será evidenciada a seguir uma breve descrição de cada um dos elementos temáticos, a fim de explicitar como as temáticas são apresentadas pelas revistas. Optou-se por exemplificar com trechos de reportagem os três elementos temáticos com maior frequência, para uma melhor apreensão de como o pai e a família são divulgados na mídia.

\subsection{Paternidade}

Esta categoria diz respeito à experiência de paternidade e o elemento temático novo pai foi o que apresentou maior número de ocorrência nas reportagens analisadas $(n=58)$. O novo pai refere-se ao estilo emergente de paternidade e se relaciona à maior igualdade na divisão de tarefas entre homens e mulheres e às mudanças nos papéis de pais e mães. Isso envolve a transformação do lugar da mulher na sociedade ocidental, a participação do pai na vida do filho desde a gravidez, bem como os sentimentos do homem durante a gestação. Assim, em um trecho de reportagem, verifica-se que 0 novo pai

é bem diferente do modelo tradicional, fica muito mais com as crianças, divide todas as tarefas e ainda ajuda em casa, todo mundo já sabe. Não é nem novo mais, já é quase velho. Afinal, que pai não participa de tudo hoje em dia? (...) (Pais \& Filhos, Agosto, 2011). 
Além disso, foi encontrado o pai como modelo $(n=48)$, que é aquele que tem seu próprio pai como exemplo de como ser pai. Esse elemento temático engloba, ainda, os valores transmitidos pelo pai, à admiração do filho pela figura paterna e à semelhança estética, profissional e comportamental entre pai e filho(a). Exemplifica-se este elemento temático com o seguinte trecho de reportagem:

(...) Você já parou para pensar que, se os pais estão cada vez mais presentes no dia a dia da família, os ensinamentos que são passados aos filhos também podem ter mudado? Se antes o pai era visto pelos pequenos como uma pessoa a ser temida, com o clássico 'espera só o seu pai chegar' sempre na ponta da língua das mães, hoje a figura paterna também é considerada a principal responsável pela transmissão dos valores (Pais \& Filhos, Agosto 2011).

Destaca-se também o elemento temático papel do pai $(n=41)$, que constitui as disponibilidades física, afetiva, emocional, financeira e temporal na criação dos filhos e a responsabilidade do pai na vida do filho. Abrange também os cuidados básicos (a alimentação da criança, por exemplo) e abertura ao mundo (estímulo à exploração do ambiente, colocando limites por meio da disciplina). O pai apresentase como tradicional, embora ofereça suporte à mãe. Segundo a fala de um pai, em entrevista para uma das revistas, "às vezes o pai está preocupado em ser o provedor da casa e não fica tão disponível para 'abraçar' a paternidade. Quando alguém decide ter filhos, é importante pensar se existe disponibilidade emocional, financeira e temporal" (Pais \& Filhos, Março, 2009).

Foi encontrado também o impacto da paternidade $(n=33)$ na vida do homem quando o mesmo relata que se emociona e se sente alegre por ser pai e feliz com as conquistas do filho. Além disso, foi identificado o impacto que o homem tem ao ser pai de crianças com deficiência (como Síndrome de Down e Paralisia Cerebral) e de gêmeos ou trigêmeos. Além disso, evidenciou-se o impacto do pai no desenvolvimento de crianças, em especial de meninas.

Constatou-se também que há o processo de se tornar pai $(n=30)$ e que os homens criam estratégias para lidar com isso, por meio de criação de blogs e livros, participação de cursos para pais, leitura a respeito de temas referentes à paternidade e assistem a filmes, como forma de preparação. Esse elemento temático envolve ainda o pai se percebendo no processo de transformação, os sentimentos gerados e a reação das pessoas quando o homem menciona que irá ser pai. Brincadeiras e esporte $(n=24)$ apareceram como aspectos importantes tanto para a relação pai-filho como para o desenvolvimento da criança. O brincar foi a atividade relatada como a mais realizada entre pai e filho e apareceu como uma forma de 
comunicação entre o homem e a criança. Também se demonstrou a importância de a criança brincar com diferentes brinquedos e os diferentes tipos de brincadeiras para meninos e para meninas, incluindo a pré-disposição genética e a influência de valores da cultura na escolha desses brinquedos. Já o esporte apareceu como meio de aproximação entre pai e filho, visto que alguns pais levam seu filho no treino do esporte que praticam e também influenciam seus filhos a torcerem pelo mesmo time.

Embora tenham sido apresentados elementos que representam questões positivas a respeito da paternidade, foram percebidas dificuldades enfrentadas pelo pai $(n=15)$, que correspondem à depressão pós-parto paterna, ao desemprego como fonte de estresse ao pai, à profissão de risco do progenitor e à preocupação do pai com a família. Refere-se à saúde do pai de modo geral, à reprodução assistida e à paternidade tardia.

Foi encontrada também a ausência do pai $(n=12)$, que diz respeito às mães que criam seus filhos sozinhas: algumas por opção, outras, não; e aos motivos que levam a uma mãe querer ser solteira. Engloba também pais que estão mais preocupados com o trabalho do que com a criação de seus filhos.

Por último, apresenta-se o elemento temático dia dos pais $(n=3)$, que se refere à visão que se tem desse dia em diferentes culturas, bem como a história de sua criação. Trata-se de uma data especial para muitos pais, os quais relatam como foi o seu dia e qual o significado que este dia tem para eles e sua família ao longo de gerações, além de ser um momento que envolve consumo e demonstrações de carinho.

\subsection{Família}

Essa categoria se refere ao contexto em que as relações pai-filho são estabelecidas e que interfere no envolvimento paterno. As relações familiares - elemento temático de maior ocorrência $(n=36)$ compreendem a união familiar, a importância da família, a relação dos pais com os filhos e entre os outros membros da família (relação avô-netos, por exemplo). Envolve amor, carinho e proximidade entre pai e filho. Isto é constatado no seguinte trecho:

Somos uma família unida. Tivemos, eu e meu irmão, pais igualmente presentes. Não sentíamos vergonha do fato de estarem ao nosso lado o tempo todo. Continuaram participando mesmo quando nos tornamos adolescentes. Era uma época sem independência, mas de total apoio. Isso significou muito. Eles eram bastante atuantes. Tanto meu pai como minha mãe também foram bem ligados a suas famílias. Ele principalmente, 
filho único, foi ligado aos meus avós. Por isso se preservou muito a união familiar (Pais \& Filhos, Julho, 2005).

A educação de filhos $(\mathrm{n}=34)$ aponta que a criação e a educação de filhos é uma tarefa de pai e de mãe. Mostra como é fundamental a conversa entre pai e filho, a explicação que o homem fornece à criança a respeito de dúvidas dela e as regras e limites que o pai coloca aos filhos. Apresenta, ainda, o pai como mediador do filho com a internet e a mídia (televisão e revista) como meio de educar. Notase, por meio do trecho a seguir, que o pai preocupa-se com a educação de seus filhos: "(...) O peso da responsa(bilidade) de educar uma outra pessoa, de alguém depender de mim, é do tamanho de uma bigorna. (...) Um pai legal é aquele que conversa, encaminha e educa de um jeito politicamente correto. Mostra o certo e o errado" (Crescer, Março, 2004).

Constata-se a associação entre conjugalidade e paternidade $(n=27)$, mostrando as possíveis transformações no casamento após o nascimento dos bebês, a importância dos filhos serem um projeto a dois, o impacto do filho na relação do casal e a influência no modo de agir. Surgiram questões relacionadas à coparentalidade e à supervalorização da maternidade. Foi verificado também o papel do pai após separação conjugal e o desejo crescente do homem em ficar com a guarda do filho. Para exemplificar, tem-se a fala de uma mãe:

Somos três mulheres loucas por nossos filhos. Também amamos nossos maridos e eles sentem o mesmo por nós. Então, por que passamos a brigar tanto depois que os bebês nasceram? Por que ficamos tão irritadas quando eles não conseguem encontrar chupetas? Por que eles ficam tão chateados com o fato de nosso entusiasmo por sexo ser igual ao nosso entusiasmo por passar roupa? (Crescer, Setembro, 2009).

Apesar das mudanças apresentadas acerca do espaço do homem e da mulher, percebeu-se diferença entre pai e mãe $(n=24)$, no que se refere às tarefas assumidas (por exemplo, foi mostrado que é difícil o homem ouvir o choro do bebê à noite e que o filho chama a mãe antes do pai) e ao jeito como o pai e a mãe realizam tais atividades: geralmente, os pais são mais práticos na realização das tarefas.

Por último, foram agrupadas questões jurídicas $(n=22)$ sobre a adoção, os direitos do pai e da mãe (licenças maternidade e paternidade), a legalização da paternidade, o pai adotivo, a paternidade e homossexualidade e a pensão alimentícia. É uma forma de as revistas serem também fontes de informação, não apenas sobre como ser pais ou agirem com a criança, mas também a respeito dos aspectos jurídicos. 


\section{Discussão}

O propósito deste estudo foi analisar o que foi publicado sobre o pai e o envolvimento paterno por duas revistas de divulgação, e discutemse aqui os elementos temáticos de maior ocorrência. Verificou-se que o assunto mais citado nas reportagens refere-se ao novo pai. Desse modo, estaria a revista retratando o pai nos tempos atuais ou "moldando" o modo de ser pai? Será que esse novo pai é uma realidade ou uma idealização? Acreditamos que não há respostas fechadas a estas perguntas e que ambas as opções podem responder a questão. Assim, o questionamento é efetuado como incentivo à reflexão crítica frente ao que é veiculado pela mídia, no caso, as revistas.

Embora o novo pai seja uma possibilidade cada vez mais presente nos lares brasileiros, o estilo tradicional ainda se faz presente (Staudt \& Wagner, 2008). No estudo de Bustamante e Trad (2005), com famílias oriundas de classes populares, a divisão sexual do trabalho evidencia-se: o pai comumente é o provedor e a mãe se responsabiliza por administrar os recursos e manter a união da família. Mesmo quando a mulher é a provedora da casa, esse papel não é tão enfatizado quanto o é para o homem. Vale ressaltar que a revista Pais \& Filhos tem um público leitor composto principalmente por mulheres de classe média e alta, escolarizadas e com renda própria, apesar de se destinar aos adultos de todas as classes sociais (Nascimento et al., 2013; Schwengber \& Silveira, 2011). O que se encontra em relação à publicidade de ambas as revistas pesquisadas diz respeito a roupas de alto custo e viagens para fora do país como opção para levar as crianças para passearem nas férias.

Assim, a mídia estudada aborda as questões referentes ao pai e ao contexto específico à qual as revistas de divulgação pesquisadas se destinam (classes média e alta), utilizando diferentes tipos de reportagens (contos, dados históricos, depoimentos, dicas, entrevistas com pais e mãe, relatos de caso por profissionais, pesquisas e propagandas). Além disso, destacam-se temas como paternidade e família, que despertam o interesse do público a que se dedicam (pais e mães).

O pai como modelo foi o segundo elemento temático que mais apareceu nas reportagens. Assim, há uma preocupação em ser um bom pai, além do desejo do próprio pai em ser um modelo para o filho. É importante mencionar Balancho (2012), o qual, em seu livro, cita a frase de James Dobson: "nós, pais, estamos tão ocupados a dar às nossas crianças o que não tivemos, que não temos tempo para Ihes dar aquilo que deram a nós" (p. 81). Logo, embora a apreensão do pai em relação ao seu desenvolvimento como tal permita uma 
reavaliação das próprias ações, ressalta-se que essa preocupação nem sempre possui uma conotação positiva.

Mesmo que tenham sido apresentadas, pelas revistas, as disponibilidades física, afetiva, financeira e temporal do pai em relação à vida dos filhos e a responsabilização pelos cuidados básicos da criança, percebe-se que o papel do pai aparece também como de homem tradicional (aquele que se preocupa com o trabalho, pouco se envolve no cuidado das crianças e assume uma postura autoritária). Pode-se entender papéis como a série de tarefas e relações esperadas de um sujeito que ocupa determinada posição social, os quais são identificados e estimulados culturalmente (Goetz \& Vieira, 2009). Quanto ao papel do pai no desenvolvimento infantil, é possível constatar que em cada contexto histórico-cultural, atribuições de papéis variam e, ao longo da história, foram esperados diferentes padrões de paternidade. A partir do século $X X$, o padrão ideal consistiu em um pai mais envolvido e com uma participação mais ativa na vida de seus filhos: um homem que brinca, instrui e se responsabiliza pelos cuidados e pela criação dos filhos (Pleck \& Pleck, 1997). Assim, existiram e ainda há distintos padrões de comportamento idealizados referentes à paternidade, assim como alguns têm coexistido (Goetz \& Vieira, 2009).

Como há variação em padrões relacionados à paternidade, transformações nas configurações familiares também ocorreram. 0 núcleo familiar da sociedade contemporânea mudou em relação à tradicional: há famílias de pais divorciados, recasados, adotivos, homossexuais, avós que cuidam dos netos, mães solteiras, pais solteiros, entre outras tantas configurações (Staudt \& Wagner, 2008). Desde o nascimento e durante toda a primeira infância, os cuidados fundamentais e estímulos necessários ao desenvolvimento infantil são geralmente fornecidos pela família, como a socialização da criança, além da educação geral, abrangendo, inclusive, a educação formal, em colaboração com a escola (Santos, Martinelli \& Monteiro, 2012). Assim, considerando a família e as relações que se estabelecem nesse sistema como principais contextos de desenvolvimento da criança, predominaram as relações familiares como tema mais citado na categoria família.

Pode-se entender que as mudanças no modelo econômico e a maior inserção da mulher no mercado de trabalho repercutem não somente na dinâmica familiar e em questões conjugais, como também na educação de filhos (Bossardi et al., 2013). Desse modo, existe uma crescente busca de informação feita pelo pai em relação à paternidade. Percebeu-se, por meio das revistas pesquisadas, que os pais se dedicam à procura de dicas sobre o cuidado paterno em sites, blogs, livros e filmes a fim de entender como podem agir com seus filhos. 
Espera-se que o pai, no que diz respeito ao processo educacional dos filhos, instrua (Lamb, 1997), corrija comportamentos, repreenda e puna as crianças quando realizam atividades impróprias (Bossardi et al., 2013). Foi visto que, embora haja diferença entre as tarefas que são feitas pelo pai, se comparado à mãe, ambos têm participação na educação de filhos. Destaca-se, dentre os resultados encontrados, que o homem coloca regras e limites à criança, buscando disciplinála. Em um estudo realizado por Bossardi et al. (2013), foi encontrada uma valorização referente à dimensão disciplina, o que corrobora com a visão tradicional de papéis parentais, no qual o pai é visto como transmissor da autoridade social.

Para exercer tarefas de educação dos filhos, é necessário que o casal se una e realize constantes negociações, entretanto a transição de um casamento sem filhos para a parentalidade é considerada uma das maiores transformações no sistema familiar (Menezes \& Lopes, 2007). Nesse sentido, aponta-se a importância da relação entre conjugalidade e paternidade. A relação conjugal sofre mudanças relacionadas à vida sexual, ao romantismo e à felicidade após o nascimento de bebês, segundo as revistas Pais \& Filhos e Crescer.

Rothman (2004), embasada em um estudo longitudinal, aponta para uma diminuição no nível da satisfação com o casamento durante a transição para a parentalidade. No entanto, Huston e Vangelisti (1995) alegam que, apesar de o casal notar um declínio no romance, percebe-se um aumento no companheirismo a partir do nascimento dos filhos. Para Hidalgo e Menendez (2003), o apoio emocional dos cônjuges, o envolvimento paterno e a concordância com a divisão das atividades domésticas podem influenciar no modo como a relação conjugal se desenvolve durante esse processo de transição.

Assim como o desenvolvimento individual, a família possui um ciclo de vida, o qual indica que: (a) as famílias necessitam se reorganizar a fim de acomodar o crescimento e a mudança de seus integrantes; e (b) o desenvolvimento, em qualquer geração da família, pode gerar impacto sobre um ou todos os seus membros (Nichols \& Schwartz, 2007). Referente às famílias com filhos pequenos, de acordo com o apontado por Nichols e Schwartz (2007), há o princípio fundamental de aceitar os novos integrantes no sistema. Nessa perspectiva, é preciso ajustar o sistema conjugal para dar espaço aos filhos, além de que o casal poderá se unir na criação dos filhos, nas tarefas financeiras e nas domésticas, bem como é possível haver 0 realinhamento dos relacionamentos com a família ampliada para incluir papéis de pai, mãe e avós, por exemplo.

Além disso, foi demonstrado, por meio das reportagens lidas, que vem crescendo a tendência de os pais ficarem com a guarda dos filhos após a separação conjugal, além de afirmarem que sua relação com seus filhos melhorou com o fim do casamento. Após o divórcio, o tempo dos pais pode ser dedicado às crianças, o que possibilita um 
aumento na intimidade e cumplicidade entre pais e filhos (Ramires, 1997).

Os resultados encontrados na presente pesquisa corroboram com os achados dos estudos realizados por Chechi e Hillesheim (2008) e Schwengber e Silveira (2011), apesar de irem de encontro ao apresentado por Nascimento et al. (2013), que afirmam que o termo pai aparece em foco somente quando se refere ao "pai jurídico" (questões relacionadas a pensão alimentícia, guarda dos filhos, reconhecimento de paternidade, separação e divisão de bens). Apesar de questões jurídicas terem aparecido nos exemplares considerados no presente trabalho, o tema predominante foi o novo pai (na categoria paternidade).

Esse estilo emergente de paternidade consiste no pai que é participativo e envolvido com a família e com os filhos, ao contrário do que é exposto por Nascimento et al. (2013), que alegam que o novo modelo de paternidade não é veiculado. A diferença entre os resultados pode ser atribuída aos possíveis exemplares examinados, uma vez que ambas as pesquisas optaram por selecionar aleatoriamente o mês, assim como aos anos pesquisados. Além disso, Chechi e Hillesheim (2008), Schwengber e Silveira (2011) e Nascimento et al. (2013) pesquisaram uma coluna específica da revista Pais \& Filhos ("Coluna de Homem") e não utilizaram a revista Crescer como fonte para análise.

Considerando que os achados das revistas escolhidas para o presente estudo vão ao encontro da literatura científica, pode-se questionar se a mídia influencia ou apenas divulga questões referentes à paternidade. Será que ela induz perspectivas e pensamentos ou transmite aquilo que as pessoas pensam e vivem? $\mathrm{Na}$ atualidade, $\mathrm{O}$ modelo masculino paterno que vem sendo publicado pela revista Pais \& Filhos é o de um pai sentimental, participativo e presente (Schwengber \& Silveira, 2011) assim como o é divulgado pela revista Crescer, em consonância com o modelo de novo homem (Ribeiro \& Siqueira, 2007).

A mídia parece não só influenciar concepções, crenças e pensamentos, mas também retratar aquilo que está ocorrendo em algumas famílias contemporâneas (mudanças de papéis e participação mais atuante do pai), corroborando com estudos científicos realizados pelos autores citados ao longo do texto. Pode-se entender que a mídia-educação constitui-se como parte dos processos de socialização inclusive das populações adultas (Bévort \& Belloni, 2009), em uma perspectiva de "pedagogias culturais", que produzem entretenimento, formação e diversão, em que são veiculados modos de ser, de viver, de sentir e de pensar (Maraschin, 2003). É preciso, então, que a apropriação dos conteúdos midiáticos seja feita de forma crítica e criativa, visto que a mídia participa da construção da subjetividade e compartilha estilos de vida (Bévort \& 
Belloni, 2009). Assim, é impossível negá-la, já que não se pode excluí-la.

\section{Considerações finais}

Constatou-se que o pai foi relatado como participativo tanto na vida do filho quanto nas demais relações familiares. Ele envolve-se nos cuidados, interage com o filho e busca ser disponível ao mesmo, responsabilizando-se por diversas atividades. Os pais que deram seus depoimentos para as revistas, de maneira geral, expressaram de forma positiva sua experiência de paternidade e os relacionamentos familiares são apresentados de modo harmônico. A paternidade como algo "mágico", idealizada e também vivenciada tão positivamente nas reportagens das revistas demonstra uma realidade, que não necessariamente é vivenciada por todos os pais. Isso não significa que os pais não sintam a "magia" da paternidade, porém o processo de se tornar pai também apresenta suas dificuldades e desafios, seus medos e angústias, questões pouco relatadas pelas revistas pesquisadas (de um total de 14 elementos temáticos, tem-se apenas um acerca das dificuldades). Além disso, quando apresentadas as dificuldades experimentadas, eram mencionadas também as superações.

É possível pensar que as revistas ressaltam aspectos positivos da paternidade para reforçar o valor da figura paterna no vínculo familiar, tornando as potencialidades de ser pai mais atrativas ao consumo quando comparadas às dificuldades da paternidade. Esse fato poderia ser tanto ferramenta de motivação para futuros pais, quanto elemento inibidor para aqueles que não se identificam com os exemplos apresentados pela revista. Por outro lado, não enfatizar os sentimentos negativos da paternidade pode provocar e manter sentimentos de culpa e mal-estar em pais que não se percebam ou não se identifiquem com os apresentados pela revista, por não se considerarem tão eficientes, amorosos ou disponíveis aos filhos. Outro aspecto que pode ser pensado refere-se à dificuldade de um sujeito expor que é cansativo ou árduo ser pai, pois há uma preocupação com o que as pessoas possam pensar a respeito dele e de sua exposição na mídia.

Nota-se que embora os temas que emergiram tenham sido agrupados em categorias e elementos temáticos há relações que podem ser estabelecidas entre eles. Por exemplo, constata-se a necessidade de (re)negociações na relação entre o casal para realizar a educação dos filhos. Além disso, percebeu-se que o envolvimento paterno está associado às relações familiares e ao modo como o casal lida com a transição de um casamento sem filhos para a paternidade e a maternidade. 
A mídia, ao popularizar conhecimentos produzidos pela ciência, atua na produção, veiculação e acessibilidade ao envolvimento paterno. Assim, as informações veiculadas são elementos que constituem o pensamento individual, grupal e coletivo. Destaca-se que as publicações das revistas analisadas são voltadas para o público de pais da classe alta e média e possivelmente essas não retratam a realidade dos pais que possuem baixa renda. Sendo assim, as revistas se mostram como um campo de estudo em que se pode buscar a construção do pensamento do senso comum acerca do envolvimento paterno, o qual precisa ser problematizado.

Nesse sentido, como citado ao longo do texto, há a pressuposição de que a mídia busca captar e apresentar mudanças sociais, assim como influenciar as ações do público alvo, seja incentivando ou coibindo determinadas práticas, modelos e concepções sociais. Essas publicações refletem mudanças sociais e econômicas, como a emancipação das mulheres e a crescente atuação das mesmas no mercado de trabalho, o que passou a exigir a participação mais ativa dos homens nos afazeres domésticos e nos cuidados das crianças, fato que parece estar sendo veiculado pela mídia. Outra constatação é que a maior pró-atividade feminina modificou as relações maritais e a própria relação dos pais (homens) com os filhos, proporcionando novas interações familiares, o que pode alterar as relações em geral, havendo novas práticas e modelos de interação social transmitidos para as crianças.

Assim, questiona-se como esses parâmetros apresentados pela mídia podem atingir as famílias que não se adequam a tais modelos propostos. Isto é, como essas se sentem, agem e se "enquadram"? Essa temática não foi foco de análise das publicações selecionadas, pois foram poucas as que citaram a ausência paterna e seus efeitos ou as dificuldades e os sentimentos negativos vivenciados pelos pais. Portanto, considera-se que essa pesquisa trouxe contribuições, tais como a identificação e descrição das mudanças nas ações paternas dos homens entre os anos de 2003 a 2013, como citado "a emergência do novo pai". Ao mesmo tempo, as limitações podem estar relacionadas às análises e efeitos dessas mudanças sobre 0 desenvolvimento infantil e sobre os pais que não se enquadram no que foi apresentado, temas que não foram aprofundados (por não terem sido o foco das revistas), mas que podem ser investigados por pesquisas futuras.

\section{Referências}

Balancho, L. S. (2012). Ser pai, hoje (9 ed.). Lisboa: Editorial Presença.

Bardin, L. (1977). Análise de conteúdo. Lisboa: Edições 70. 
Beltrame, G. R., \& Bottoli, C. (2010). Retratos do envolvimento paterno na atualidade. Barbarói, 32, 205-226.

Bévort, E., \& Belloni, M. L. (2009). Mídia-educação: conceitos, história, perspectivas. Educação e Sociedade, 30(190), 10811102.

Bossardi, C. N., Gomes, L. B., Vieira, M. L., \& Crepaldi, M. A. (2013). Engajamento paterno no cuidado a crianças de 4 a 6 anos. Psicologia Argumento, 31, 237-246.

Bossardi, C. N., \& Vieira, M. L. (2010). Cuidado paterno e desenvolvimento infantil. Revista de Ciências Humanas, 44(1), 205-221.

Bueno, R. K. (2014). Relações entre envolvimento paterno com filhos adotivos e estrutura familiar (Dissertação de Mestrado). Universidade Federal de Santa Catarina, Florianópolis, Brasil.

Bustamante, V., \& Trad, L. A. B. (2005). Participação paterna no cuidado de crianças pequenas: um estudo etnográfico com famílias de camadas populares. Cadernos de Saúde Pública, 21(6), 1865-1874.

Chechi, P., \& Hillesheim, B. (2008). Paternidade e mídia: representações sobre o pai na contemporaneidade. Barbarói, (28), 89-108.

Crepaldi, M. A., Andreani, G., Hammes, P. S., Ristof, C. D., \& Abreu, S. R. de. (2006). A participação do pai nos cuidados da criança, segundo a concepção de mães. Psicologia em Estudo, 11(3), 579-587.

Dessen, M. A., \& de Oliveira, M. R. (2013). Envolvimento Paterno Durante o Nascimento dos Filhos: Pai "Real" e "Ideal" na Perspectiva Materna. Psicologia: Reflexão e Crítica, 26(1), 184192.

Dubeau, D., Devault, A., \& Paquette, D. (2009). L'engagement paternel, un concept aux multiples facettes. In D. Dubeau, $A$. Devault, \& G. Forget (Eds.). La paternité au XXI sièle (pp. 7198). Québec, Canada: Les Presses de l'Université Laval.

Fagundes, A. J. F. M. (1999). Descrição, definição e registro de comportamento (12 ed.). São Paulo: Edicon.

Goetz, E. R., \& Vieira, M. L. (2009). Pai real, pai ideal: O papel paterno no desenvolvimento infantil. Curitiba: Juruá.

Gomes, A. J. S., \& Resende, V. R. (2004). O pai presente: o desvelar da paternidade em uma família contemporânea. Psicologia: Teoria \& Pesquisa, 20(2), 119-125.

Hennigen, I. (2010). Especialistas advertem: o pai é importante para o desenvolvimento infantil. Fractal: Revista de Psicologia, 22(1), 169-184.

Hidalgo, M., \& Menendez, S. (2003). La pareja ante la llegada de los hijos. Evolución de la relación conyugal durante el proceso de 
converterse em padre y madre. Infância y Aprendizaje, 26(4), 469-483.

Huston, T. L., \& Vangelisti, A. L. (1995). How parenthood affects marriage. In: M. A. Fitzpatrick, \& A. L. Vangelisti (Orgs.). Explaining family interactions. (pp. 147-176). Thousand Oaks: Sage Publications.

Lamb, M. E. (1997). Fathers and child development: an introductory overview and guide. In: M. E. Lamb (Ed), The role of the father in child development (3 ed., pp. 1-18). New York: John Wiley \& Sons, Inc.

Lamb, M. E., Pleck, J. H., Charnov, E. L., \& Levine, J. A. (1985). Paternal Behavior in Humans. American Zoologist, 25, 883894.

Manfroi, E. C., Macarini, S. M., \& Vieira, M. L. (2011). Comportamento parental e o papel do pai no desenvolvimento infantil. Revista Brasileira de Crescimento E Desenvolvimento Humano, 21(1), 59-69.

Maraschin, C. (2003). Psicologia e educação: pontuações temporais. In C. Maraschin, L.B.L. Freitas, \& D. C. Carvalho (Org.) Psicologia e Educação: multiversos sentidos, olhares e experiências (pp. 233-242). Porto Alegre: Editora da UFRGS, 233-242.

Menezes, C. C., \& Lopes, R. C. S. (2007). Relação conjugal na transição para a parentalidade: gestação até dezoito meses do bebê. Psico-USF, 12(1), 83-93.

Nascimento, A. R. A. do, Vieira, G. T., Mesquita, A. C. R., Gomes, M. M. L. O., Silva, M.C., \& Alves, R. G. S. (2013). Representações sociais de paternidade na revista Pais \& Filhos (1969-2008). Psicologia Argumento, 31(73), 205-213.

Nichols, M. P., \& Schwartz, R. C. (2007). Terapia familiar - Conceitos e métodos. Porto Alegre: Artmed.

Oliveira, A. G., \& Silva, R. R. (2011). Pai contemporâneo: Diálogos entre pesquisadores brasileiros no período de 1998 a 2008. Psicologia Argumento, 29(66), 353-360.

Paquette, D., \& Bigras, M. (2010). The risky situation: A procedure for assessing the father-child activation relationship. Early Child Development and Care, 180(1\&2), 33-50.

Paquette, D., Bolté, C., Turcotte, G., Dubeaud, D., \& Bouchard, C. (2000). A new typology of fathering: defining and associated variables. Infant and Child Development, 9(1), 13-230.

Pleck, J. H., \& Pleck, E. H. (1997). Fatherhood ideals in United States: historical Dimensions. In: M. E. Lamb (Ed.). The role of the father in child development (3 ed., pp. 33-48). New York: John Wiley \& Sons, Inc.

Ramires, V. (1997). O exercício da paternidade hoje. Rio de Janeiro: Rosa dos Tempos. 
Ribeiro, C. R, Siqueira, V. H. F. (2007). O novo homem na mídia: resignificações por homens docentes. Revista Estudos Feministas, 15(1), 217-141.

Rothman, A. D. (2004). The nature and predition of marital change across the transition to parenthood. Dissertation Abstracts International: section B: The sciences and engineering, 65(2B), 1038.

Santos, A. A. A., Martinelli, S. C., \& Monteiro, R. M. (2012). Suportes e recursos familiares: Relações com o contexto escolar. In: M. N. Baptista, \& M. L. M. Teodoro (Orgs.). Psicologia de família: Teoria, avaliação e intervenção. Porto Alegre: Artmed.

Schwengber, M. S. V., \& Silveira, C. C. (2011). O pai presente: Um modelo masculino em crescente em evidência na mídia. Relatório de pesquisa EFDeportes.com, Revista Digital. Buenos Aires, 15(154), http://www.efdeportes.com/

Staudt, A. C. P., \& Wagner, A. (2008). Paternidade em tempos de mudança. Psicologia: Teoria e Prática, 10(1), 174-185.

Vieira, M. L., Crepaldi, M. A., Bossardi, C. N., Gomes, L. B., Bolze, S. D. A., \& Piccinini, C. (2013). Paternity in the Brazilian Context. In M. L. Seidl-de-Moura (Ed.), Parenting in South American and African Contexts (pp. 35-64). Croácia: InTech.

\author{
Endereço para correspondência \\ Isabella Goulart Bittencourt \\ Universidade Federal de Santa Catarina \\ Núcleo de Estudos e Pesquisas em Desenvolvimento Infantil \\ Departamento de Psicologia - Centro de Filosofia e Ciências Humanas \\ Campus Universitário, Trindade, CEP 88040-970, Florianópolis - SC, Brasil \\ Endereço eletrônico: isabellagoulartb@gmail.com

\section{Larissa Paraventi} \\ Universidade Federal de Santa Catarina \\ Núcleo de Estudos e Pesquisas em Desenvolvimento Infantil \\ Departamento de Psicologia - Centro de Filosofia e Ciências Humanas \\ Campus Universitário, Trindade, CEP 88040-970, Florianópolis - SC, Brasil \\ Endereço eletrônico: larissaparaventi@hotmail.com

\section{Rovana Kinas Bueno} \\ Universidade Federal de Santa Catarina \\ Núcleo de Estudos e Pesquisas em Desenvolvimento Infantil \\ Departamento de Psicologia - Centro de Filosofia e Ciências Humanas \\ Campus Universitário, Trindade, CEP 88040-970, Florianópolis - SC, Brasil \\ Endereço eletrônico: rovanak@gmail.com

\section{Gabriela Mello Sabbag} \\ Universidade Federal de Santa Catarina \\ Núcleo de Estudos e Pesquisas em Desenvolvimento Infantil \\ Departamento de Psicologia - Centro de Filosofia e Ciências Humanas \\ Campus Universitário, Trindade, CEP 88040-970, Florianópolis - SC, Brasil \\ Endereço eletrônico: gabi_s@hotmail.com

\section{Maria josé Louise Caro Schulz} \\ Universidade Federal de Santa Catarina \\ Núcleo de Estudos e Pesquisas em Desenvolvimento Infantil
}


Departamento de Psicologia - Centro de Filosofia e Ciências Humanas

Campus Universitário, Trindade, CEP 88040-970, Florianópolis - SC, Brasil

Endereço eletrônico: mc.schulz@hotmail.com

\section{Mauro Luís Vieira}

Universidade Federal de Santa Catarina

Núcleo de Estudos e Pesquisas em Desenvolvimento Infantil

Departamento de Psicologia - Centro de Filosofia e Ciências Humanas

Campus Universitário, Trindade, CEP 88040-970, Florianópolis - SC, Brasil

Endereço eletrônico: maurolvieira@gmail.com

Recebido em: $21 / 08 / 2014$

Reformulado em: 23/02/2015

Aceito para publicação em: 24/03/2015

\section{Notas}

* Graduanda de Psicologia pela Universidade Federal de Santa Catarina, Florianópolis, Santa Catarina, Brasil.

** Graduanda de Psicologia pela Universidade Federal de Santa Catarina, Florianópolis, Santa Catarina, Brasil.

*** Doutoranda em Psicologia pela Universidade Federal de Santa Catarina, Florianópolis, Santa Catarina, Brasil.

**** Doutoranda em Psicologia pela Universidade Federal de Santa Catarina, Florianópolis, Santa Catarina, Brasil.

***** Doutoranda em Psicologia pela Universidade Federal de Santa Catarina, Florianópolis, Santa Catarina, Brasil.

******* Doutor em Psicologia pela Universidade de São Paulo, Professor Titular do Departamento de Psicologia e do Programa de Pós-Graduação em Psicologia da Universidade Federal de Santa Catarina, Florianópolis, Santa Catarina, Brasil.

1 O termo "pais" será utilizado neste artigo como sinônimo da palavra "pai" no plural. 